\title{
Sensory-motor performance in seven-year-old children born extremely preterm
}

\section{Lönnberg, Piia}

2018-05

Lönnberg , P , Niutanen , U , Parham , L D , Wolford , E , Andersson , S , Metsäranta , M \& Lano , A 2018 , ' Sensory-motor performance in seven-year-old children born extremely preterm ' , Early Human Development, vol. 120 , pp. 10-16 . https://doi.org/10.1016/j.earlhumdev.2018.03.012

http://hdl.handle.net/10138/302393

https://doi.org/10.1016/j.earlhumdev.2018.03.012

publishedVersion

Downloaded from Helda, University of Helsinki institutional repository.

This is an electronic reprint of the original article.

This reprint may differ from the original in pagination and typographic detail.

Please cite the original version. 


\title{
Sensory-motor performance in seven-year-old children born extremely preterm
}

\author{
Piia Lönnberg, ${ }^{\mathrm{a}, *}$, Ulla Niutanen ${ }^{\mathrm{a}}$, L. Diane Parham ${ }^{\mathrm{b}}$, Elina Wolford ${ }^{\mathrm{c}}$, Sture Andersson ${ }^{\mathrm{a}}$, \\ Marjo Metsäranta ${ }^{\mathrm{a}}$, Aulikki Lano ${ }^{\mathrm{a}}$ \\ ${ }^{\text {a } C h i l d r e n ' s ~ H o s p i t a l, ~ P e d i a t r i c ~ R e s e a r c h ~ C e n t e r, ~ U n i v e r s i t y ~ o f ~ H e l s i n k i ~ a n d ~ H e l s i n k i ~ U n i v e r s i t y ~ H o s p i t a l, ~ H e l s i n k i, ~ F i n l a n d ~}$ \\ ${ }^{\mathrm{b}}$ Department of Pediatrics, School of Medicine, University of New Mexico, Albuquerque, United States \\ ${ }^{\mathrm{c}}$ Department of Psychology and Logopedics, University of Helsinki, Helsinki, Finland
}

\section{A R T I C L E I N F O}

\section{Keywords:}

Extremely preterm

Sensory-motor

Visual-motor

Somatosensory

Children

\begin{abstract}
A B S T R A C T
Background: Children born preterm are prone to motor problems. Research on their motor performance has, however, rarely been integrated with sensory processing.

Aim: To examine sensory-motor performance in children born extremely preterm (EPT).

Method: In a longitudinal prospective cohort study, 49 EPT (born $<28$ gestational weeks; 32 boys and 17 girls) and 33 term-born (16 boys and 17 girls) children were assessed with six individual subtests from the Sensory Integration and Praxis Tests at the age of 7.0 to 7.3 years.

Results: The rate of test z-scores indicating dysfunction [from -2 standard deviations (SD) to $<-1$ SD for mild and $<-2$ SD for moderate-to-severe] was significantly higher in EPT children than in term-born children in all the subtests. When comparing mean performance adjusted for gender and mother's education, EPT children performed worse than term-born children in Design Copying (z-score difference - 0.83; 95\% confidence interval -1.32 to -0.34$)$, Motor Accuracy $(-0.82 ;-1.26$ to -0.38$)$, Postural Praxis $(-0.95 ;-1.45$ to -0.45$)$, Manual Form Perception $(-0.59 ;-1.12$ to -0.06$)$, and Finger Identification $(-0.88 ;-1.45$ to -0.31$)$. Additional adjustment for Full-Scale Intelligence Quotient rendered difference in Manual Form Perception nonsignificant.

Conclusion: Seven-year-old EPT children perform worse than their term-born peers in tests for visual-motor, somatosensory, and motor planning performance.
\end{abstract}

\section{Introduction}

Children born preterm are at a greater risk than their term-born peers of developing poor motor coordination in both gross and fine motor domains [1,2]. At school-age, the prevalence of mild-to-moderate motor impairment in preterm children is approximately 40\% [2], and poor motor coordination persists throughout childhood [1] into adulthood [3]. Motor coordination skills are positively associated with attention and executive function [4], which constitute a specific area of weakness among very preterm children [5]. Motor coordination in conjunction with perceptual abilities in preterm children has been widely studied regarding visual-motor integration [6].

The context for preterm children's motor and other neurodevelopmental problems most likely lies within altered brain white and grey matter structures [7], cerebellar injury [8], and disrupted thalamocortical connections [9]. The mechanisms for how these micro- and macrostructural alterations of the developing brain become evident as mild or moderate motor impairment are, however, unclear. One underlying factor for preterm children's motor problems may be poor integration of sensations from the body and the environment. The sensory integration (SI) concept draws attention to a person's abilities to organize sensations for perception, modulation, and sensory-motor functions. This ongoing process influences the dynamic use of the body and the limbs spatially in relation to each other and the environment, affecting daily activities and behaviors, and learning new skills [10,11].

The role of sensory processing in motor performance is rarely addressed in studies on preterm children. The purpose of our study was to describe both sensory and motor performance in seven-year-old children born extremely preterm (EPT) without major neurosensory disabilities [cerebral palsy, Full-Scale Intelligence Quotient (FSIQ) $<70$, blindness or deafness]. Based on previous research and our clinical experience, we hypothesized that EPT children would perform worse

\footnotetext{
Abbreviations: EPT, extremely preterm; FSIQ, Full-Scale Intelligence Quotient; SD, standard deviation; SIPT, Sensory Integration and Praxis Tests

* Corresponding author at: Children's Hospital, Helsinki University Hospital, Po. Box. 280, 00029 HUS, Helsinki, Finland.

E-mail address: piia.lonnberg@fimnet.fi (P. Lönnberg).
} 


\section{Extremely preterm group}

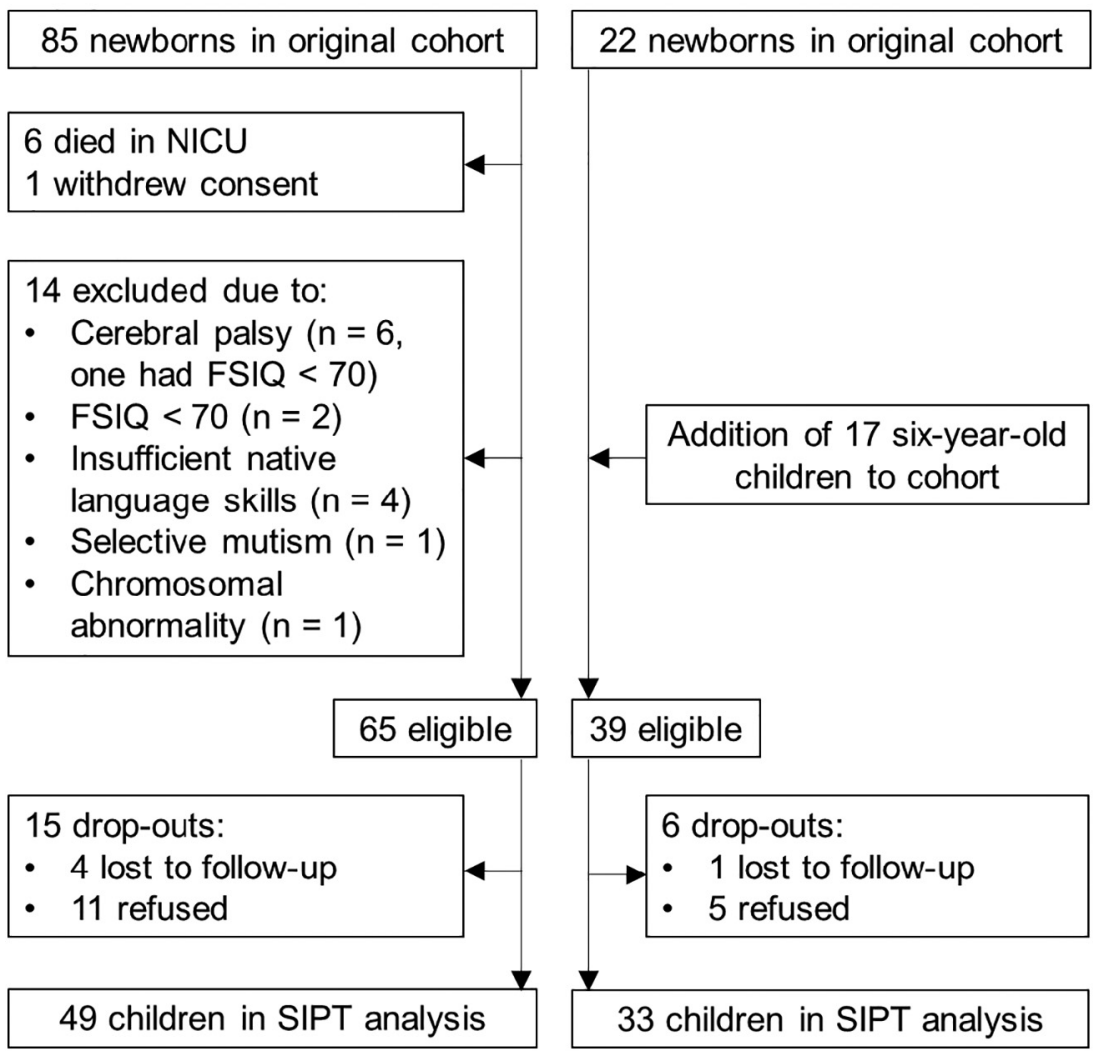

Fig. 1. Flow-chart of the study groups.

FSIQ, Full-Scale Intelligence Quotient; NICU, neonatal intensive care unit; SIPT, Sensory Integration and Praxis Tests.

than their term-born peers in tests of visual-motor, somatosensory (i.e., proprioception, haptic perception, and passive tactile perception), and bilateral integration abilities. This study is one of the first to explore the sensory processing difficulties that may underlie motor impairment experienced by EPT children.

\section{Material and methods}

\subsection{Study design and participants}

This study included 49 EPT children and 33 term-born children (inclusion, exclusion criteria and drop-outs summarized in Fig. 1). The children originally participated in a longitudinal prospective cohort study of 85 EPT children who were consecutively born at $<28$ weeks' gestation between May 2006 and September 2008 and were actively treated after birth at the neonatal intensive care unit of the Helsinki University Hospital, Finland (KeKeKe Study - Extremely Preterm Birth and Development of the Central Nervous System [12]). Controls of the original cohort were 39 children born healthy at term age between September 2006 and June 2009 in the Hospital District of Helsinki and Uusimaa, Finland. They were recruited to the study shortly after birth from the maternity ward of the Department of Obstetrics, Helsinki University Hospital or at six years of age through an advertisement that was delivered to nursery schools in Helsinki and also distributed by an association of premature babies' parents (Fig. 1). Inclusion criteria included gestational age from $37^{+0}$ to $42^{+0}$ weeks, birth weight > $2500 \mathrm{~g}$ and no need for observation or treatment in the neonatal ward.

The Ethics Committee for gynecology and obstetrics, pediatrics and psychiatry of the Hospital District of Helsinki and Uusimaa granted ethical approval for the original study and the follow-up at 6-7 years. Parents or guardians of the participating children provided written informed consent to participation and publication of the results. In addition, all children received age-appropriate information about the study and provided consent to participate in the study.

\subsection{Clinical data}

Obstetric, neonatal, maternal, and paternal data were obtained from the hospital records and parental questionnaires. When available, gestational age was determined from the first-trimester ultrasound. Small for gestational age was defined as birth weight z-score $<-2$ SD according to the Finnish growth reference data [13]. The highest grade of intraventricular hemorrhage in serial cranial ultrasound during the neonatal period was recorded. White matter injury in brain magnetic resonance imaging at term equivalent age was classified into four categories from none to severe [12,14]. Information regarding hearing and vision were collected from the child's health records and, when necessary, a visual acuity test and cover tests for strabismus were performed.

Cognitive development (Full-Scale, Performance, and Verbal Intelligence Quotient) was measured at 6-7 years [median (IQR): EPT children $6.5(0.2)$ years, term-born children $6.5(0.1)$ years, $p=0.80$ ] with three Performance (Block Design, Matrix Reasoning, and Picture Completion) and two Verbal (Information and Vocabulary) subtests of the Finnish edition of the Wechsler Preschool and Primary Scale of Intelligence - Third Edition (WPPSI-III) [15] or the Wechsler Intelligence Scale for Children - Fourth Edition (WISC-IV) [16]. Missing subtest data were imputed by the mean of the available Performance or Verbal subtest scores. 
Table 1

Characteristics of the participating extremely preterm born and term-born children and the extremely preterm born drop-outs.

\begin{tabular}{|c|c|c|c|c|c|}
\hline Characteristic & $\begin{array}{l}\text { Extremely preterm born children } \\
\mathrm{n}=49\end{array}$ & $\begin{array}{l}\text { Term-born children } \\
\mathrm{n}=33\end{array}$ & $p^{\mathrm{a}}$ & $\begin{array}{l}\text { Extremely preterm born drop-outs } \\
\mathrm{n}=15\end{array}$ & $p^{\mathrm{b}}$ \\
\hline Boys & $32(65 \%)$ & $16(49 \%)$ & 0.13 & $8(53 \%)$ & 0.40 \\
\hline Age at SIPT assessment, median (IQR), y & $7.1(0.1)$ & $7.1(0.2)$ & 0.12 & . & . \\
\hline \multicolumn{6}{|l|}{ Neonatal demographics } \\
\hline Gestational age, median (IQR), wk & $26.4(1.9)$ & $40.3(1.1)$ & $<0.001$ & $26.7(1.3)$ & 0.28 \\
\hline Birth weight, mean (SD), g & $851(183)$ & $3629(396)$ & $<0.001$ & $916(180)$ & 0.20 \\
\hline Small for gestational age & $7(14 \%)$ & $0(0 \%)$ & 0.04 & $1(7 \%)$ & 0.67 \\
\hline Twins & $12(25 \%)$ & $0(0 \%)$ & 0.001 & $0(0 \%)$ & 0.05 \\
\hline Mother primipara & $30(61 \%)$ & $17(52 \%)$ & 0.38 & $8(53 \%)$ & 0.32 \\
\hline Mother smoking during pregnancy & $5(10 \%)$ & $2(6 \%)$ & 0.70 & $5(33 \%)$ & 0.05 \\
\hline \multicolumn{6}{|l|}{ Neonatal morbidity } \\
\hline Respiratory distress syndrome & $40(82 \%)$ & . & . & $6(40 \%)$ & 0.003 \\
\hline Bronchopulmonary dysplasia at $36^{+0}$ gwk $^{\mathrm{c}}$ & $25(54 \%)$ & . & . & $3(21 \%)$ & 0.03 \\
\hline Necrotizing enterocolitis & $3(6 \%)$ & . & . & $1(7 \%)$ & 1 \\
\hline Patent ductus arteriosus & $39(80 \%)$ & . & . & $11(73 \%)$ & 0.72 \\
\hline Retinopathy of prematurity ${ }^{c}$ & $14(29 \%)$ & . & . & $2(13 \%)$ & 0.32 \\
\hline Intraventricular hemorrhage & & & . & & 0.54 \\
\hline No & $30(61 \%)$ & . & & $12(80 \%)$ & \\
\hline Grade I-II & $13(27 \%)$ & . & & $2(13 \%)$ & \\
\hline Grade III-IV & $6(12 \%)$ & . & & $1(7 \%)$ & \\
\hline White matter injury in MRI at TEA ${ }^{c}$ & & & . & & 0.13 \\
\hline No & $27(59 \%)$ & . & & $10(91 \%)$ & \\
\hline Mild & $17(37 \%)$ & . & & $1(9 \%)$ & \\
\hline Moderate & $2(4 \%)$ & . & & $0(0 \%)$ & \\
\hline Severe & $0(0 \%)$ & . & & $0(0 \%)$ & \\
\hline Mother's education $^{c}$ & & & 0.003 & & 0.52 \\
\hline High school or lower & $23(47 \%)$ & $5(15 \%)$ & & $3(27 \%)$ & \\
\hline Bachelor degree & $16(33 \%)$ & $11(33 \%)$ & & $5(46 \%)$ & \\
\hline Master degree or higher & $10(20 \%)$ & $17(52 \%)$ & & $3(27 \%)$ & \\
\hline Father's education $^{c}$ & & & 0.02 & & 0.20 \\
\hline High school or lower & $25(53 \%)$ & $11(33.3 \%)$ & & $6(60 \%)$ & \\
\hline Bachelor degree & $16(34 \%)$ & $9(27.3 \%)$ & & $1(10 \%)$ & \\
\hline Master degree or higher & $6(13 \%)$ & $13(39.4 \%)$ & & $3(30 \%)$ & \\
\hline \multicolumn{6}{|l|}{ Cognitive development at $6-7 y^{c}$} \\
\hline Full-Scale IQ, mean (SD) & $97(11)$ & $106(10)$ & $<0.001$ & . & . \\
\hline Performance IQ, mean (SD) & $91(12)$ & $104(13)$ & $<0.001$ & . & . \\
\hline Verbal IQ, median (IQR) & 107 (19) & $113(8)$ & 0.09 & . & . \\
\hline
\end{tabular}

Data are n (\%) unless otherwise specified.

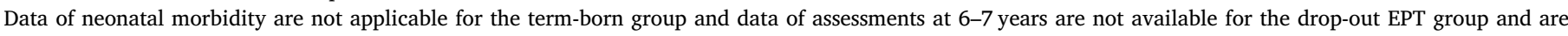
marked with “.”.

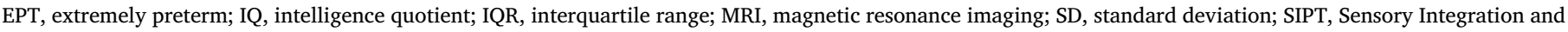
Praxis Tests; TEA, term equivalent age.

a Comparison of the participating EPT and term-born control children.

b Comparison of the participating and drop-out EPT children.

c Data not available for all children as follows: Bronchopulmonary dysplasia (3 participating EPT and 1 drop-out EPT), Retinopathy of prematurity (1 participating

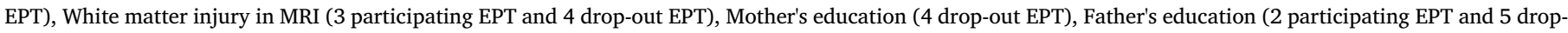
out EPT), and Cognitive ability testing (3 EPT and 1 control).

\subsection{Sensory Integration and Praxis Tests}

The Sensory Integration and Praxis Tests (SIPT) [10] are a diagnostic tool for 4 years 0 months to 8 years 11 months old children. Based on sensory integration theory, SIPT assesses performance irregularities in learning and behavior through aspects of sensory processing in visual, proprioceptive, vestibular and tactile systems with 17 individually scored subtests. Each subtest's raw score is standardized with a normative data sample of 1997 US children using a computerized scoring system to obtain $\mathrm{z}$-scores [mean $=0$, standard deviation $(\mathrm{SD})=1]$. The $\mathrm{z}$-score of each SIPT subtest may range from -3.0 to $+3.0 \mathrm{SD}$ and indicates severe dysfunction $(-3.0$ to -2.5$)$, definite dysfunction $(-2.5$ to -2.0$)$, mild dysfunction or mild difficulty $(-2.0$ to -1.0$)$, typical functioning $(-1.0$ to +1.0$)$, above average $(+1.0$ to +2.0 ) or advanced functioning $(+2.0$ to +3.0$)$. Extreme values are suppressed since, according to the test protocol, test scores above +3.0 SD are reported as +3.0 and scores below -3.0 are reported as -3.0 . Each subtest discriminates between dysfunctional and normal performance $(p<0.01)$ and has very high inter-rater reliability $(0.94$ to 0.99) $[10]$.
For the present study, we selected six subtests of the SIPT to measure performance problems that we have observed in EPT children in clinical practice. One experienced, SIPT-certified examiner (UN), who was blinded to group status, conducted all the assessments in one-time meetings when the children were at the age of 7 years 0 months to 7 years 3 months. The administered SIPT subtests included:

1. Design Copying - the child replicates two-dimensional drawings (accuracy and strategy, i.e. reversals, inversions, segmentations, lateralization, and right-to-left orientation, recorded); measures visual-motor integration (i.e., visual-motor coordination and visualperceptual abilities) and visuopraxis.

2. Motor Accuracy - the child traces a curving line with a pencil, one hand at a time (accuracy and time recorded); measures visual-motor coordination.

3. Postural Praxis - the child imitates unusual, mainly upper limb, postures with increasing difficulty requiring e.g. crossing of body midline and differentiated finger positions (time limited); measures the use of proprioceptive information for motor planning.

4. Manual Form Perception - the child manually explores unfamiliar 

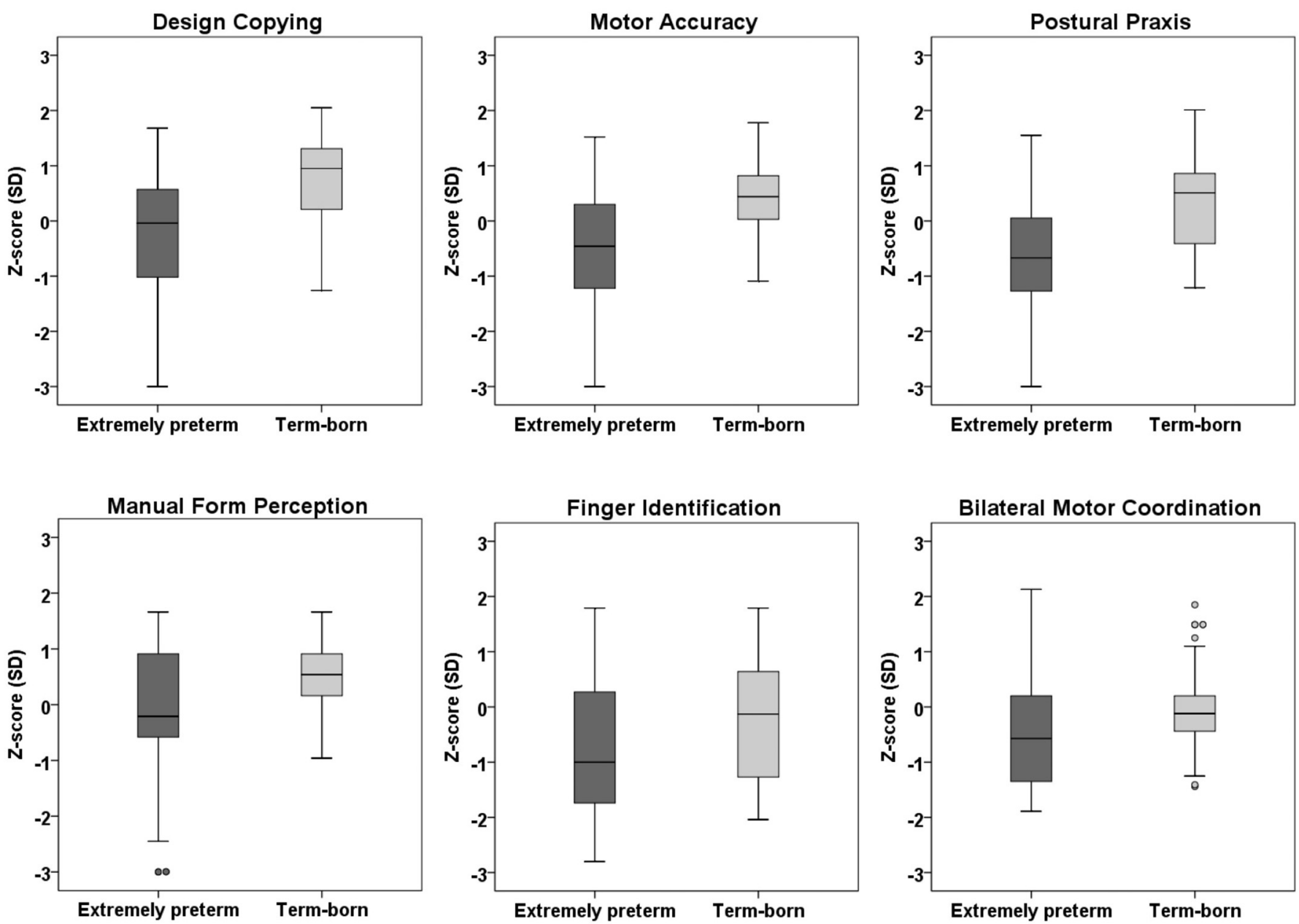

Fig. 2. Sensory Integration and Praxis Tests z-scores in the studied extremely preterm born and term-born children.

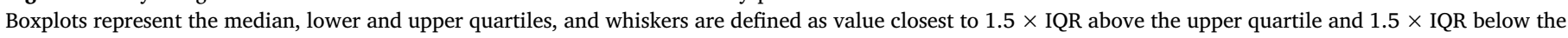
lower quartile. Outliers are marked with dots. IQR, interquartile range.

two-dimensional forms without seeing them, one hand at a time, to find a similar picture (touch and vision) or a matching pair with the opposite hand (touch only); measures haptic perception and visualization abilities.

5. Finger Identification - the child indicates which finger or two fingers the examiner touches at volar side (vision occluded); measures tactile perception.

6. Bilateral Motor Coordination - the child imitates rhythmic reciprocal movements of hands or feet (smoothness, continuity, and accuracy recorded); measures functional integration of the two sides of the body [10].

Test data were not available for one EPT child for Finger Identification, and another EPT child refused to complete Postural Praxis and Bilateral Motor Coordination. Other subtest data from these children were included in the analyses.

\subsection{Statistical analyses}

Statistical analyses were performed with SPSS version 23 (IBM SPSS Statistics, IBM Corporation, US). We compared characteristics between the participating EPT and term-born children and, further, between the analyzed groups and drop-outs (separately for EPT and term-born children) to assess potential bias in the study groups. Group characteristics were compared with Student's $t$-test, Mann-Whitney U, $\chi^{2}$ or Fisher's exact test when appropriate. Normality of distribution for continuous variables was assessed visually from histograms or by Shapiro-Wilk test. For continuous variables with normal distribution, means (SD) are reported; otherwise medians (IQR). Categorical data are presented with $\mathrm{n}(\%)$. Significance was set at 0.05 using two-tailed comparison.

We calculated odds ratios for dysfunction between the EPT and term-born groups according to each performed SIPT subtest with cumulative logistic regression or, in case of results in only two categories, with binary logistic regression. Testing of parallel lines (proportional odds assumption) was computed for each cumulative regression model.

SIPT subtest z-scores of the EPT and term-born groups were compared with unadjusted and adjusted linear models. Based on previous research, gender and mother's education (in three categories; refer to Table 1) served as confounding factors in the adjusted Model 1, and additionally FSIQ (as a continuous variable) in the adjusted Model 2. The assumptions (equality of variances and normality of the test residual distribution) of the analyses were verified visually from graphs. Due to missing FSIQ data, three EPT children and one term-born child were excluded from Model 2. The unadjusted model and Model 1 yielded essentially similar results when including or excluding these three children. Therefore, these models include all children assessed with the subtest in question.

To assess the effect size of the differences in the SIPT subtest $\mathrm{z}$ scores, we calculated Cohen's d-values, where generally $d=0.2$ represents a small effect, $d=0.5$ a medium effect, and $d=0.8$ a large effect. Cohen's d was defined as mean difference divided by pooled 
standard deviation, i.e. the square root of the average of the squared standard deviations.

\section{Results}

Characteristics of the studied EPT children and their term-born peers along with comparison of the participating and drop-out EPT children are presented in Table 1. The EPT children who participated in the study were more often twins, were less often exposed to maternal smoking during pregnancy, and more often expressed respiratory distress syndrome and bronchopulmonary dysplasia than those who dropped out. The participating term-born children had higher gestational age (median 40.3 vs. $38.6, p=0.008$ ) than the term-born dropouts. Other demographic characteristics of the participating and dropout groups did not differ significantly. None of the EPT children had severe white matter injury at term age. No child was blind or deaf; one EPT child used hearing aids and 11 EPT children had strabismus and/or were using glasses, two of whom had decreased corrected visual acuity (0.4 to 0.5). Excluding these two EPT children yielded no significant changes in the results below.

EPT children expressed wide variance in their sensory-motor performance (Fig. 2). Definite-to-severe dysfunction was evident in Design Copying, Motor Accuracy, Postural Praxis, Manual Form Perception, and Finger Identification among the EPT children (ranging from $8 \%$ to $21 \%$ of this sample), and in Finger Identification among their term-born controls (6\%) (Table 2). Subsequently, EPT children had significantly higher, up to fourteen-fold, odds for dysfunction in all the performed SIPT subtests (borderline significant in Finger Identification). The odds ratio for Manual Form Perception could, however, not be calculated in the absence of any dysfunction among the term-born children (Table 2).

When comparing test z-scores, EPT children performed significantly worse in all the performed SIPT subtests except Bilateral Motor Coordination (Table 3 and Fig. 2). All the significant group differences in the unadjusted model remained significant after adjusting for gender and mother's education. After additional adjustment for FSIQ, the group difference in Design Copying and Postural Praxis was attenuated but remained significant, and was no longer significant in Manual Form Perception (Table 3).

\section{Discussion}

In this study of EPT children without major neurosensory disabilities or severe white matter injury, sensory-motor performance was studied using a standardized test battery for children. Comparisons to a term-born control group were performed using both categorized and continuous data to assess differences in rates of dysfunction as well as in mean performance. The rate of mild to severe dysfunction was significantly higher in EPT children than their term-born controls in all the studied tests with 20 to $50 \%$ of EPT children in the "dysfunctional" performance range as opposed to 0 to $30 \%$ of term-born children. Regarding mean performance, the test scores of EPT children were 0.6 to $1.0 \mathrm{SD}$ lower than the scores of the controls, with medium to large effect sizes in Design Copying, Motor Accuracy, Postural Praxis, Manual Form Perception, and Finger Identification.

Our results are consistent with previous studies [17-19] that have used SIPT in the assessment of school-aged preterm children. Goyen et al. [19] studied Design Copying and Postural Praxis among other tests in eight-year-old EPT children with and without developmental coordination disorder. They revealed worse performance scores in reference to a full-term control group in praxis and visual processing in EPT children, and EPT children with developmental coordination disorder scored even lower than those without it. DeMaio-Feldman [17] studied Manual Form Perception and Finger Identification among other somatosensory processing tests in a group of seven-year-old very low birth weight children and found mean scores of almost 1 SD below the normative mean.

The greatest difference between EPT and term-born children was found in visual-motor coordination tests: Motor Accuracy and Design Copying. Motor Accuracy yielded the largest effect size and odds ratio for dysfunction of the performed SIPT subtests, suggesting impaired pen skills among extremely preterm children. Previous studies have shown clear evidence of visual-motor integration deficits in very preterm children [6], and handwriting is one of their special challenges [18]. Handwriting is a perceptual-motor skill that requires, in addition to visual-motor coordination, the utilization of multiple sensory inputs such as sensory awareness of fingers in tactile and kinesthetic/proprioceptive domains, along with motor planning, cognitive and

Table 2

Rates of dysfunction according to the SIPT subtests in 49 extremely preterm born children and 33 term-born controls with odds ratios (OR) for dysfunction.

\begin{tabular}{|c|c|c|c|c|c|c|}
\hline & & $\begin{array}{l}\text { Extremely preterm born children } \\
\mathrm{n}(\%)\end{array}$ & $\begin{array}{l}\text { Term-born children } \\
\text { n (\%) }\end{array}$ & OR & $95 \%$ CI & $p$ \\
\hline \multirow[t]{2}{*}{ Design Copying } & Typical-to-advanced functioning & $35(71.4 \%)$ & $32(97 \%)$ & 13.0 & $1.6-105$ & 0.02 \\
\hline & Mild dysfunction & $10(20.4 \%)$ & $1(3 \%)$ & & & \\
\hline \multirow[t]{3}{*}{ Motor Accuracy } & Typical-to-advanced functioning & $34(69.4 \%)$ & $32(97 \%)$ & 14.3 & $1.8-116$ & 0.01 \\
\hline & Mild dysfunction & $10(20.4 \%)$ & $1(3 \%)$ & & & \\
\hline & Definite-to-severe dysfunction & $5(10.2 \%)$ & 0 & & & \\
\hline \multirow[t]{3}{*}{ Manual Form Perception } & Typical-to-advanced functioning & $39(80 \%)$ & $33(100 \%)$ & NA & NA & $0.02^{\mathrm{b}}$ \\
\hline & Mild dysfunction & $3(6 \%)$ & 0 & & & \\
\hline & Definite-to-severe dysfunction & $7(14 \%)$ & 0 & & & \\
\hline \multirow[t]{3}{*}{ Finger Identification $^{\mathrm{a}}$} & Typical-to-advanced functioning & $24(50 \%)$ & $23(70 \%)$ & 2.5 & $1.0-6.2$ & 0.05 \\
\hline & Mild dysfunction & $14(29 \%)$ & $8(24 \%)$ & & & \\
\hline & Definite-to-severe dysfunction & $10(21 \%)$ & $2(6 \%)$ & & & \\
\hline Bilateral Motor Coordination ${ }^{\mathrm{a}}$ & Typical-to-advanced functioning & $29(60 \%)$ & 30 (91\%) & 6.6 & $1.7-24.5$ & $0.005^{c}$ \\
\hline
\end{tabular}

Comparison with cumulative logistic regression unless otherwise specified. Typical-to-advanced functioning is indicated with a test score of -1 SD or higher, mild dysfunction from $-2 \mathrm{SD}$ to less than $-1 \mathrm{SD}$, and definite-to-severe dysfunction less than $-2 \mathrm{SD}$ in accordance to the normative data mean. OR $>1$ indicates more dysfunction in EPT children compared to term-born controls. CI, confidence interval; EPT, extremely preterm; NA, not applicable; SD, standard deviation; SIPT, Sensory Integration and Praxis Tests.

${ }^{\mathrm{a}} \mathrm{EPT} \mathrm{n}=48$.

${ }^{\mathrm{b}}$ Fisher's exact test.

c Binary logistic regression. 
Table 3

Extremely preterm born vs. term-born group comparison for SIPT subtest z-scores (SD) with linear model adjusting for confounding factors.

\begin{tabular}{|c|c|c|c|c|c|c|c|c|c|c|}
\hline & \multicolumn{3}{|c|}{ Unadjusted } & \multirow[t]{2}{*}{ Effect Size } & \multicolumn{3}{|c|}{$\begin{array}{l}\text { Model 1: } \\
\text { Adjusted for gender and mother's education }\end{array}$} & \multicolumn{3}{|c|}{$\begin{array}{l}\text { Model 2: } \\
\text { Adjusted for gender, mother's education, and } \\
\text { FSIQ }^{\text {b }}\end{array}$} \\
\hline & B & $95 \% \mathrm{CI}$ & $p$ & & B & $95 \% \mathrm{CI}$ & $p$ & B & $95 \% \mathrm{CI}$ & $p$ \\
\hline Design Copying & -1.03 & $\begin{array}{l}-1.49 \text { to } \\
-0.58\end{array}$ & $<0.001^{* *}$ & 1.05 & -0.83 & -1.32 to -0.34 & $0.001^{*}$ & -0.60 & -1.11 to -0.10 & 0.02 \\
\hline Motor Accuracy & -0.94 & $\begin{array}{l}-1.33 \text { to } \\
-0.55\end{array}$ & $<0.001^{* *}$ & 1.11 & -0.82 & -1.26 to -0.38 & $<0.001^{* *}$ & -0.80 & -1.27 to -0.32 & $0.001^{*}$ \\
\hline Postural Praxis ${ }^{\mathrm{a}}$ & -1.01 & $\begin{array}{l}-1.45 \text { to } \\
-0.56\end{array}$ & $<0.001^{* *}$ & 1.04 & -0.95 & -1.45 to -0.45 & $<0.001^{*}$ & -0.65 & -1.17 to -0.13 & 0.02 \\
\hline Manual Form Perception & -0.67 & $\begin{array}{l}-1.15 \text { to } \\
-0.20\end{array}$ & $0.006^{*}$ & 0.68 & -0.59 & -1.12 to -0.06 & $0.03 *$ & -0.40 & -0.96 to 0.15 & 0.15 \\
\hline Finger Identification ${ }^{\mathrm{a}}$ & -0.59 & $\begin{array}{l}-1.11 \text { to } \\
-0.07\end{array}$ & $0.03^{*}$ & 0.49 & -0.88 & -1.45 to -0.31 & $0.003^{*}$ & -0.89 & -1.50 to -0.28 & $0.005^{*}$ \\
\hline $\begin{array}{l}\text { Bilateral Motor } \\
\text { Coordination }^{\mathrm{a}}\end{array}$ & -0.41 & -0.84 to 0.02 & 0.06 & 0.44 & -0.38 & -0.86 to 0.11 & 0.13 & -0.28 & -0.81 to 0.25 & 0.29 \\
\hline
\end{tabular}

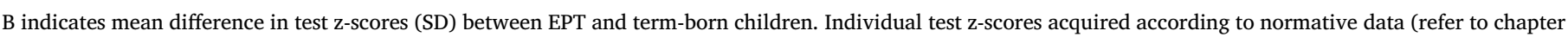
"Method"; normative mean $=0$ ).

CI, confidence interval; EPT, extremely preterm; FSIQ, Full-Scale Intelligence Quotient; SD, standard deviation; SIPT, Sensory Integration and Praxis Tests.

a Data not available for one EPT child.

b Additional three EPT children and one term-born child excluded due to missing FSIQ data.

$* p<0.05$.

** $p<0.001$.

perceptual skills, and sustained attention [20]. Performance in SIPT subtests Motor Accuracy and Finger Identification were found to directly correlate with handwriting legibility and speed in preterm born first-graders [18]. The poor performance of our EPT cohort in Design Copying, Motor Accuracy, and Finger Identification further supports these previous findings.

Motor planning and proprioceptive abilities have been only scarcely studied in preterm children. In our study, one third of EPT children showed mild to severe dysfunction in imitating postures in the Postural Praxis subtest. By linking sensory perception and motor execution, Postural Praxis examines the ability to use proprioceptive information and visual cues for planning and producing novel limb movements. These abilities are essential when regarding motor skills from a developmental aspect. During the process of motor skill learning, visual control, which is important at start, gradually decreases while the importance of proprioceptive feedback increases. Meanwhile, the significance of cognitive regulation and conscious attention decreases, and, at the last step after automatization of the movement, the fully organized motor pattern is adapted to dynamically respond to the spatiotemporal constraints of the environment [21]. In this learning process and afterwards, when employing the acquired skill, proprioceptive processing is essential for movement fluency and accuracy [22].

The difference in bilateral integration performance between EPT and term-born children was more modest than we hypothesized probably because no definite-to-severe dysfunction was found. This might be due to limited discrimination since the smoothness of reciprocal movements in Bilateral Motor Coordination is somewhat challenging to score even with standardized scoring criteria. Future studies on the topic could benefit from videoing the performance allowing more accurate scoring.

To our knowledge, this is the first study to compare haptic perceptual abilities between preterm and term-born children. In Manual Form Perception, all term-born children showed either typical or above average haptic functioning while $14 \%$ of EPT children showed definiteto-severe dysfunction suggesting that problems would be evident in everyday life. Haptic perception is required in activities of daily living (ADL), e.g. buttoning a shirt or tying shoelaces, but the extent of the association between haptic perception and ADL skills in children remains unknown. We studied sensory-motor skills per se, but their impact on ADL and academic skills remains an important prospect for future research.

The generalizability of our results applies to a population of EPT children without major disability and major brain injury since we excluded children with cerebral palsy and/or moderate to severe cognitive impairment. Nevertheless, the included EPT children showed rather wide variance in performance as has been demonstrated before [23].

This study has limitations. The parents of the term-born children were relatively highly educated compared to the parents of the EPT children, and the ratio of boys to girls was lower in term-born than EPT children. Significant differences in performance remained, however, after adjusting the main analyses for gender and mother's education. Our study included visual and somatosensory aspects of motor performance, but omitted vestibular system contributions, which is also essential since balance problems have been reported in preterm children [1]. In addition, while the SIPT subtests were chosen to measure quite selective abilities, many of them, especially Design Copying, Postural Praxis, and Manual Form Perception, also require broader cognitive and sensory functions. EPT children had significantly lower FSIQs than term-born children, which resulted mainly from a lower Performance IQ reflecting perceptual ability, as also observed previously in children born very preterm [23]. Differences in cognitive skills, even within normal range, accounted for some of the performance differences in Design Copying, Postural Praxis, and Manual Form Perception, but it is also noteworthy, that the abilities assessed by the SIPT subtests most likely affect performance in tests of cognitive development. Taking cognition into account when assessing differences in sensory-motor performance is one of the strengths of our study.

Despite the well-known high prevalence of motor problems among preterm children [1,2], these problems are often considered merely from a motor skill level point of view. Here, we introduce evidence that EPT children express poorer performance than term-born peers in a variety of sensory-motor skills that are prone to affect performance in school and everyday life. A better understanding of how motor performance requires the utilization of multisensory information processing would be advantageous when developing or targeting interventions. 


\section{Conflict of interest statement}

\section{None declared.}

\section{Acknowledgements}

We thank Dr. Petri Rahkonen for gathering neonatal data, Dr. Taina Autti and Dr. Leena Valanne for classifying the brain magnetic resonance images, and biostatistician Tero Vahlberg for statistical consultation. This research was supported by Arvo and Lea Ylppö Foundation, Finnish Medical Foundation, and the Foundation for Pediatric Research. The foundations were not involved in the study design, data collection or analyses, or interpretation or publication of the results. Finally, we sincerely thank all the families who participated in this study.

\section{References}

[1] J.F. de Kieviet, J.P. Piek, C.S. Aarnoudse-Moens, J. Oosterlaan, Motor development in very preterm and very low-birth-weight children from birth to adolescence: a meta-analysis, JAMA 302 (2009) 2235-2242.

[2] J. Williams, K.J. Lee, P.J. Anderson, Prevalence of motor-skill impairment in preterm children who do not develop cerebral palsy: a systematic review, Dev. Med. Child Neurol. 52 (2010) 232-237.

[3] K.L. Poole, L.A. Schmidt, C. Missiuna, S. Saigal, M.H. Boyle, R.J. Van Lieshout, Motor coordination difficulties in extremely low birth weight survivors across four decades, J. Dev. Behav. Pediatr. 36 (2015) 521-528.

[4] N. Marlow, E.M. Hennessy, M.A. Bracewell, D. Wolke, EPICure Study G., Motor and executive function at 6 years of age after extremely preterm birth, Pediatrics 120 (2007) 793-804.

[5] C.S. Aarnoudse-Moens, N. Weisglas-Kuperus, J.B. van Goudoever, J. Oosterlaan, Meta-analysis of neurobehavioral outcomes in very preterm and/or very low birth weight children, Pediatrics 124 (2009) 717-728.

[6] C.J.A. Geldof, A.G. van Wassenaer, J.F. de Kieviet, J.H. Kok, J. Oosterlaan, Visual perception and visual-motor integration in very preterm and/or very low birth weight children: a meta-analysis, Res. Dev. Disabil. 33 (2012) 726-736.

[7] C. Nosarti, E. Giouroukou, E. Healy, L. Rifkin, M. Walshe, A. Reichenberg, et al., Grey and white matter distribution in very preterm adolescents mediates neurodevelopmental outcome, Brain 131 (2008) 205-217.
[8] C. Limperopoulos, G. Chilingaryan, N. Sullivan, N. Guizard, R.L. Robertson, A.J. du Plessis, Injury to the premature cerebellum: outcome is related to remote cortical development, Cereb. Cortex 24 (2014) 728-736.

[9] G. Ball, L. Pazderova, A. Chew, N. Tusor, N. Merchant, T. Arichi, et al., Thalamocortical connectivity predicts cognition in children born preterm, Cereb. Cortex 25 (2015) 4310-4318.

[10] A.J. Ayres, The Sensory Integration and Praxis Tests (SIPT) Manual, Los Angeles, USA, Western Psychological Services, 1989.

[11] R.C. Schaaf, J.P. Burke, E. Cohn, T.A. May-Benson, S.A. Schoen, S.S. Roley, et al., State of measurement in occupational therapy using sensory integration, Am. J. Occup. Ther. 68 (2014) e149-153.

[12] P. Rahkonen, P. Nevalainen, L. Lauronen, E. Pihko, A. Lano, S. Vanhatalo, et al., Cortical somatosensory processing measured by magnetoencephalography predict neurodevelopment in extremely low-gestational-age infants, Pediatr. Res. 73 (2013) $763-771$.

[13] U. Sankilampi, M. Hannila, A. Saari, M. Gissler, L. Dunkel, New population-based references for birth weight, length, and head circumference in singletons and twins from 23 to 43 gestation weeks, Ann. Med. 45 (2013) 446-454.

[14] L.J. Woodward, P.J. Anderson, N.C. Austin, K. Howard, T.E. Inder, Neonatal MRI to predict neurodevelopmental outcomes in preterm infants, N. Engl. J. Med. 355 (2006) 685-694.

[15] D. Wechsler, P. Heiskari, B. Jakobson, A. Marila, Wechsler Preschool and Primary Scale of Intelligence - III. Finnish Translation, Helsinki, Finland, Psykologien Kustannus Oy, 2009.

[16] D. Wechsler, Wechsler Intelligence Scale for Children - IV. Finnish Translation, Helsinki, Finland, Psykologien Kustannus Oy, 2010.

[17] D. DeMaio-Feldman, Somatosensory processing abilities of very low-birth weight infants at school age, Am. J. Occup. Ther. 48 (1994) 639-645.

[18] K.P. Feder, A. Majnemer, D. Bourbonnais, R. Platt, M. Blayney, A. Synnes, Handwriting performance in preterm children compared with term peers at age 6 to 7 years, Dev. Med. Child Neurol. 47 (2005) 163-170.

[19] T.A. Goyen, K. Lui, J. Hummell, Sensorimotor skills associated with motor dysfunction in children born extremely preterm, Early Hum. Dev. 87 (2011) 489-493.

[20] K.P. Feder, A. Majnemer, Handwriting development, competency, and intervention, Dev. Med. Child Neurol. 49 (2007) 312-317.

[21] S.A. Goodgold-Edwards, S.A. Cermak, Integrating motor control and motor learning concepts with neuropsychological perspectives on apraxia and developmental dyspraxia, Am. J. Occup. Ther. 44 (1990) 431-439.

[22] U. Proske, S.C. Gandevia, The proprioceptive senses: their roles in signaling body shape, body position and movement, and muscle force, Physiol. Rev. 92 (2012) 1651-1697.

[23] L. Luoma, E. Herrgard, A. Martikainen, Neuropsychological analysis of the visuomotor problems in children born preterm at $<$ or $=32$ weeks of gestation: a 5-year prospective follow-up, Dev. Med. Child Neurol. 40 (1998) 21-30. 